\title{
Strategi pengembangan layanan perpustakaan dalam menggunakan media sosial di perguruan tinggi
}

\section{Suherman}

\begin{abstract}
This article discusses information technology development strategies for higher education library services. college libraries have specific strategies in developing information technology-based library services more in facing the current industrial revolution 4.0 era in order to improve the quality of services in order to support their educational institutions in realizing "world class university". Therefore libraries based on information technology or better known as digital libraries are very potential to be developed to support a variety of academic activities, especially those relating to the management and utilization of these works. The focus of library digitalization is on four main things, namely procurement, processing, circulation and reference. In this service, digital libraries must be developed optimally in accordance with the advances in information technology today. The use of social media, such as Whatsapp, Line and Twitter, should be considered as an alternative in strategies for developing technology-based library services in universities.
\end{abstract}

Keyword: Information Technology (IT), Library, Digital, whatsapp based service

\section{Pendahuluan}

Ledakan informasi (information exploision) sudah melanda dunia dimana setiap saat dunia terus dibanjiri dengan informasi dari berbagai sumber atau media bahkan yang belum dapat dipastikan kebenannya. Ribuan, jutaan bahkan milyaran informasi yang benar berbaur dengan informasi yang diragukan kebenarannya. Oleh karena itu, sudah menjadi keniscayaan bagi hampir setiap insan yang hidup di zaman ini bahwa mereka sulit atau hampir tidak dapat hidup tanpa bersinggungan dengan teknologi informasi. Hampir setiap saat dan setiap aktifitas yang 
mereka lakukan dalam keseharian mereka selalu saja terkontaminasi dengan yang namanya teknologi informasi. Hal ini disebabkan karena perkembangan teknologi telah mentransformasikan cara pembelajaran abad milenial ini di mana sumber kekuatan utama adalah pengetahuan atau informasi dan teknologi yang menjadi salah satu cara untuk menjangkau semua pihak dalam memberikan informasi, tidak terkecuali pendidikan tinggi terutama dalam proses pembelajaran (www.kemdikbud.go.id, 2016).

Fenomena ini menuntut manusia terutama insan yang berpendidikan, untuk dapat memimilih dan memilah serta menganalisa setiap informasi yang diterima serta memiliki strategi untuk menemukan informasi yang diinginkan secara cepat dan tepat. Hal ini dilakukan agar mereka tidak tersesat oleh informasiinformasi yang sengaja dibuat oleh pihak-pihak tertentu dengan tujuan untuk menyesatkan mereka. Lebih-lebih lagi, selaku umat Islam, kita harus ingat bahwa Allah SWT juga telah mengingatkan hambanya terhadap hal tersebut tadi, sebagaimana telah disebutkan dalam firmanNya dalam surat al-Hujarat, ayat 6 yang maksudnya adalah:

Wahai orang-orang yang beriman, jika datang kepadamu orang fasik membawa suatu berita, maka periksalah dengan teliti agar kamu tidak menimpakan suatu musibah kepada suatu kaum tanpa mengetahui keadaannya yang menyebabkan kamu menyesal atas perbuatanmu itu. (QS. 49:6). ( Deaprtemen Agama RI. Alquran dan Tertjemahnya, Surat Al-Hujarat Ayat 6, 1990)

Dalam dunia pendidikan, terutama pendidikan tinggi, sivitas akademika sudah terbiasa dengan berbagai istilah teknologi informasi dan komunikasi (TIK), seperti e-school, e-learning, virtual learning, online learning, e-resources, web based learning atau berbagai istilah lainnya yang sudah begitu akrab di telinga 
mereka. Lebih jauh lagi berbagai jenis informasi dalam berbagai media sangatlah dibutuhkan oleh sivitas akademika guna menunjang kelancaran sistem pendidikan, penelitian serta pengabdian kepada masyarakat dalam rangka menunjang Tri Darma Perguruan Tinggi. Segenap sivitas akademika seharusnya lebih dapat memanfaatkan informasi yang tersedia di perpustakaan yang pada umumnya sudah terjamin kebenarannya disamping mereka juga dapat mamanfaatkan sarana akses informasi yang disediakan perpustakaan untuk menemukan informasi ke berbagai tempat dan sumber baik secara manual ataupun daring (online) (Susana Rini Kristanti, 2016).

Misi utama perpustakaan masih tetap yaitu menyediakan informasi yang terbaik bagi pemuustakanya namun kemajuan Teknologi Informasi telah menambah dimensi baru tentang tugas perpustakaan dan pustakawan yang terkesan belum siap menghadapinya. Alhasil misi ini terkesan sulit untuk diwujudkan. Hal ini disebabkan banyak perpustakaan belum siap menghadapi perubahan. Anggaran masih terbatas bahkan persentase dari keseluruhan anggaran dari lembaga induknya sangat kecil.

Sebagai landasan hukum, Undang-Undang No 43 tahun 2007 tentang perpustakaan BAB V pasal 14, ayat 3 menyatakan bahwa "Setiap perpustakaan mengembangkan layanan perpustakaan sesuai dengan kemajuan teknologi informasi dan komunikasi". Kemudian dipertegas lagi dalam BAB VII pasal 14 ayat 3, yang berbunyi, "Perpustakaan perguruan tinggi mengembangkan layanan perpustakaan berbasis teknologi informasi dan komunikasi".

Berdasarkan hal tersebut di atas maka sudah seyogianyalah perpustakaan perguruan tinggi memiliki strategi-strategi khusus dalam mengembangakan layanan perpustakaan yang berbasis teknologi informasi lebih-lebih dalam menghadapai era revolusi industri 4.0 sekarang ini guna meningkatkan kualitas layanan 
agar dapat menunjang lembaga pendidikannnya dalam mewujudkan world class university.

\section{Kajian Pustaka}

\section{Implementasi Teknologi Informasi di Perguruan Tinggi}

Menurut Pendit (2008) berdasarkan jenis-jenis perpustakaan yang ada, perpustakaan perguruan tinggi merupakan perpustakaan yang sangat berkebutuhan akan pengembangan perpustakaan digital. Dalam sejarahnya juga, bahwa awal dari pembangunan perpustakaan digital seperti Electronic Library (ELib) dan Digital Library (D-Lib) dari lingkungan perguruan tinggi. Hal ini disebabkan karena salah satu tujuan perpustakaan perguruan tinggi adalah untuk mendukung tercapainya tujuan tri darma perguruan tinggi yaitu pendidikan dan pengajaran, penelitian serta pengabdian pada masyarakat dimana di perguruan tinggilah banyak lahir rekaman-rekaman intelektual yang dikelola dan dimanfaatkan, baik dalam jurnal, berbagai hasil penelitian, skripsi, tesis, disertasi, makalah-makalah, dan sebagainya. Oleh karena itu perpustakaan yang berbasis teknologi informasi atau yang lebih dikenal dengan perpustakaan digital sangat potensial untuk dikembangkan guna mendukung berbagai kegiatan akademis, khususnya yang berkaitan dengan manajemen dan pemanfaatan hasil karya-karya tersebut tadi.

Berbagai jenis informasi yang dihasilkan Perpustakaan Perguruan Tinggi baik yang dihasilkan oleh lembaga itu sendiri, dari proses pengadaan (pembelian, tukar menukar atau hadiah) atau langganan wajib disimpan (deposit) pada lembaga induk tersebut. Sumber informasi tersebut selanjutnya akan digunakan oleh sivitas akademika untuk mendukung proses pembelajaran di perguruan tinggi tersebut. Oleh karena itu perpustakaan perguruan tinggi diharapkan secepat mungkin dapat menyesuaikan diri dengan perkembangan teknologi untuk 
mendukung kegiatan pemenuhan informasi dan mendesiminasikan sumber-sumber informasi tersebut. Pendit (2007) juga menambahkan bahwa perpustakaan perguruan tinggi juga merupakan salah satu perpustakaan yang sangat mudah beradaptasi dan mengikuti perkembangan teknologi informasi. Dari aspek infrastruktur TI, perpustakaan perguruan tinggi lebih siap untuk mengembangkan konsep perpustakaan digital dibandingkan jenis perpustakaan lainnya.

Penerapan teknologi informasi di perguruan tinggi dapat diimplementasikan dengan konsep digitalisasi perpustakaan yang bertujuan untuk (Hasanah, 2010):

a. Desiminasi karya-karya ilmiah yang dimiliki oleh sivitas akademika secara daring (online), sehingga karya-karya ilmiah ini dapat dimanfaatkan secara maksimal oleh masyarakat baik secra interrnal maupun eksternal, baik dalam lingkup, lokal, nasional maupun internasional;

b. Membangun kerjasama (network) dengan lembaga-lembaga research dan perguruan tinggi lain baik dalam dan luar negeri, guna pengembangan kolekksi virtual yang dimiliki;

c. Disebabkan informasi dapat diperoleh melalui berbagai sumber/media, perpustakaan digital tidak hanya mengelola karya ilmiah yang berbentuk teks.

Selain itu, perpustakaan perguruan tinggi merupakan bentuk sinergitas dari tiga elemen, yakni pustakawan, mahasiswa dan fakultas/program studi yang terdapat di perguruan tinggi. Pihak perpustakaan berkolaborasi dengan unit-unit lain untuk menyediakan koleksi elektronik yang dapat mendukung proses pembelajarannya. ( Johnson, Kay and Magusin, Elaine)

Pengelolaan bermacam koleksi karya intelektual civitas akademika dikategorikan berdasarkan jenis informasinya, kemudian didigitalkan untuk dilayankan kembali kepada sivitas 
akademika atau pemustaka. Karya-karya tersebut kemudian dapat dikumpulkan ke dalam repository perguruan tinggi yang mencakup antara lain skripsi, tesis, disertasi, hasil penelitian, karya ilmiah dosen dan karyawan (artikel-artikel jurnal ilmiah), grey literature (karya sivitas akademika yang tidak diterbitkan seperti laporan, orasi ilmiah), prosiding dan klipping.(Mukhlis, 2016)

\section{Target Penerapan TI dalam bidang Layanan}

Secara umum target penerapan TI di perpustakaan ini adalah pada pada hal-hal pokok di empat titik sentral kegiatan perpustakaan yang antara lain adalah sebagaimana dikemukakan oleh Arief Surachman (2018):

\section{a. Layanan Sirkulasi}

Penerapan TI dalam bidang layanan sirkulasi bisa mencakup berbagai aspek seperti layanan peminjaman dan pengembalian (sirkulasi), statistik pengunjung, administrasi keanggotaandan lain sebagainya. Di samping itu dapat juga dimanfaatkan untuk layanan pinjam antar perpustakaan (inter library loan) yang lebih mudah dan cepat. Teknologi terkini juga telah memungkinkan adanya self-services (pinjam atau kembali secara mandiri secara nonstop) dalam layanan sirkulasi melalui fasilitas barcoding dan RFID (Radio Frequency Identification). Penerapan teknologi komunikasi pun sudah mulai digunakan seperti penggunaan SMS, WA, Twitter, Line, Faksimili dan Internet.

\section{b. Layanan Referensi \& Hasil-hasil Penelitian}

Penerapan TI dalam bidang referensi dan hasil-hasil penelitian dapat dilihat dari availibilitas akses ke penelusuran sumber-sumber referensi elektronik / digital dan koleksi lainnya 
melalui kamus elektronik, direktori elektronik, peta elektronik, hasil penelitian dalam bentuk digital, dan lain-lain.

\section{c. Pengadaan}

Bagian Pengadaan juga sangat terbantu dengan adanya teknologi informasi ini. Selain dapat menggunakan TI untuk melakukan penelusuran koleksi-koleksi perpustakaan yang dibutuhkan, bagian ini juga dapat memanfaatkannya untuk menampung berbagai ide dan usulan kebutuhan perpustakaan oleh pengguna. Kerjasama pengadaan juga lebih mudah dilakukan dengan adanya TI ini.

d. Layanan Journal / Majalah / Berkala, Multimedia / AudioVisual

Pengguna layanan journal, majalah, berkala akan sangat terbantu apabila perpustakaan mampu menyediakan kemudahan dalam akses ke dalam journal-journal elektronik, baik itu yang diakses dari database lokal, global maupun yang tersedia dalam format compact disk dan disket. Demikian juga dengan layanan multimedia/audio-visual yang dulu lebih dikenal sebagai layanan "non book material" adalah layanan yang secara langsung bersentuhan dengan TI. Bahkan silang layan dan layanan penelusuran informasi pun bisa dimanfaatkan oleh pengguna dengan bantuan teknologi informasi seperti internet.

\section{e. Layanan Pengolahan Bahan Pustaka}

Selain hal-hal sebagaimana yang dikemukakan oleh Arief Surachman ada hal penting lain yang memang sudah menjadi bagian penting dalam proses digitalisasi perpustakaan yaitu pengolahan bahan pustaka. Dalam hal ini pengolahan dapat menjadi lebih mudah karena kita dapat melakukan copy cataloging baik melalui perpustakaan-perpustakaan dalam jaringan kerjasama ataupun e-catalog dari penerbit. Selain itu, dengan 
adanya jaringan internet pustakawan dapat menentukan nomor klasifikasi dengan lebih cepat dan akurat dengan memanfaatan langganan E-DDC, misalnya.

\section{Pembahasan}

Perpustakaan perguruan tinggi saat ini mulai menyadari bahwa dalam rangka memberikan nuansa baru terhadap layanan yang dimilikinya sudah seharusnya memikirkan pengoptimalan penggunaan teknologi informasi. Sebagian perpustakaan perguruan tinggi bahkan sudah berupaya mengangkat tema digital library atau perpustakaan digital sebagai bagian dari sistem terbaru layanan pemustaka dalam mengantisipasi globalisasi informasi. Namun demikian, sebenarnya masih ada keraguan pemahaman mengenai format digital library secara benar, jangan sampai apa yang dibangun hanya sekedar digital collection belum sampai pada sebuah sistem digital library yang dimaksudkan oleh para tokoh/ahli perpustakaan.

Sebagaimana telah dipaparkan pada bagian terdahulu bahwa fokus digitalisasi perpustakaan adalah pada empat hal pokok yaitu pengadaan, pengolahan, sirkulasi dan referensi. Sebenarnya inti dari layanan perpustakaan, apa pun jenisnya ialah layanan pemustaka. Oleh karena itu target pengembangan perpustakaan perguruan tnggi harusnya memang difokuskan pada layanan ini. Dari empat golongan layanan di atas yang tergolong pada layanan pemustaka yaitu layanan sirkulasi dan layanan referensi. Pada dua layanan ini perpustakaan dapat dinilai seberapa baikkah layanan yang diberikan untuk para pemustakanya. Pada layanan inilah selanjutnya perpustakaan digital harus dikembangkan secara optimal sesuai dengan kemajuan teknologi informasi saat ini.

1. Web-based digital Library 
Layanan pemustaka ini sebenarnya dapat diintergrasikan dengan layanan pemustaka berbasis website. Dengan adanya website tersebut segala jenis layanan dapat dioptimalkan melalui website perpustakaan dalam memberikan layanan kepada pemustaka perpustakaan. Selain itu pemustaka juga dapat mengetahui status suatu koleksi yang ada atau tersedia, ataupun sedang pinjam disamping memesan koleksi yang diinginkan via website perpustakaan. Website yang dimiliki tersebut selanjutnya dapat berfungsi sebagai perpustakaan digital dimana pemustaka tidak perlu datang secara fisik ke perpustakaan. Mereka hanya perlu mengakses website perpustakaan dengan menggunakan laptop (note book), komputer (desktop) atau smart phone untuk dapat mengakses koleksi digital perpustakaan untuk menunjang proses pembelajaran mereka. Jadi, dengan cara ini mereka perpustakaan seakan-akan telah berada dalam genggaman mereka. Lebih-lebih lagi di era mobile techology sekarang tampaknya perpustakaan digital merupakan format ideal perpustakaan yang diimpikan pada masyarakat perguruan tinggi. Seluruh sivitas akademika dapat mengakses koleksi perpustakaan tanpa dibatasi oleh jarak dan waktu.

Salah satu model aplikasi yang sudah dikembangkan saat ini oleh Perpustakaan Nasional RI adalah aplikasi iPusnas yang dapat didownload dengan mudah melalui aplikasi App Store atau Google Play pada smart phone android. Dengan aplikasi ini pengguna smart phone android dapat mengakses dengan mudah koleksi-koleksi digital baik berupa buku ataupun jurnal hanya melalui gengaman tangan mereka.

Dengan adanya website ini juga perpustakaan dapat memberikan layanan pesan pinjam, ekstension atau layanan delivery service terhadap koleksi yang dimiliki meskipun bisa jadi pada layanan delivery service ini menghendaki kepada biaya tersendiri yang harus ditanggung oleh pemustaka. 
Disamping itu, kemajuan teknologi smart phone juga dapat dioptimalkan guna menunjang layanan berbasis web. Salah satu contoh adalah pemesanan buku yang ingin dipinjam, pengecekan status pinjaman atau meminta layanan delivery service buku melalui smart phone yang mereka miliki. Kalau kita contohkan pada kasus yang lain, pemesan tiket online seperti pesawat terbang dan kereta api atau revservasi kamar hotel bahkan sampai pada transaksi perbankan pun dapat dilakukan secara online melalui smart phone kita dengan cara yang cukup mudah dan cepat. Jadi bukan suatu hal yang mustahil jika konsep-konsep tersebut juga dapat diaplikasikan di perpustakaan terutama perpustakaan perguruan tinggi. Memang tidak dapat dipungkiri dengan aplikasi web ini kemungkinan tingkat kunjungan pemustaka secara fisik akan berkurang, namun sistem tetap akan mencatat frekuensi kunjungan secara elektronik yang pada akhirnya juga dapat meningkatkan rangking webometrik suatu perpustakaan dan perguruan tinggi yang bersangkutan.

Satu hal yang sudah menjadi trend tenaga pengajar (dosen) yang melek teknologi dewasa ini adalah penggunaan bahan ajar digital berbasis android. Perpustakaan dapat bekerjasama dengan dosen di perguruan tinggi untuk bersinergi dalam memberikan referensi kepada mahasiswa dengan menggunakan aplikasi berbasis android ataupun smart phone. Dengan aplikasi ini mahasiswa dapat berinteraksi langsung dengan dosen baik dalam hal perkuliahan dan penyelesaian tugas secara online dengan didukung oleh referensi online terkait yang dimiliki baik oleh dosen yang bersangkutan ataupun referensi digital yang dimiliki oleh perpustakaan.

\section{Whatsapp based Service}

WhatsApp atau lebih populer disingkat WA adalah aplikasi pesan instan untuk smart phone, jika dicermati dari fungsinya WA hampir sama dengan aplikasi SMS yang biasa kita gunakan di 
ponsel lama. Akan tetapi WA tidak membutuhkan pulsa, tetapi data internet. Jadi, pada aplikasi ini kita tidak usah khawatir tentang jumlah karakter yang kita kirimkan karena tidak dibatasi, selama kita masih memiliki cukup data internet. (https://dailysocial.id/post/apa-itu-whatsapp (diakses pada: 05/10/2018)

Walaupun masih sejenis aplikasi pesan instan, sesuatu yang unik dari WhatsApp karena sistem pengenalan kontak, verifikasi dan pengiriman pesan tetap dilakukan melalui nomor ponsel yang mesti didaftarkan terlebih dahulu disebabkan model ini tidak sama dengan versi BBM yang mengharuskan adanya PIN, ataupun LINE yang selain memerlukan nomor ponsel juga menginginkan pada e-mail serta nama pengguna.

Layanan pemustaka berbasis Whatsapp sangat efektif digunakan karena Whatsapp sudah sangat populer di kalangan sivitas akademika, baik mahasiswa, dosen maupun tenaga kependidikan lainnya. Lebih-lebih lagi berdasarkan Kompas.com., WhatsApp menangani lebih dari 60 miliar pertukaran pesan antarpengguna di seluruh dunia dimana pertumbuhan ini diramalkan bakal terus meningkat, seiring penetrasi internet yang semakin luas (Kompas, 2018). Bahkan menurut penelitian yang dilakukan We Are Social, perusahaan media asal Inggris yang bekerja sama dengan Hootsuite, rata-rata orang Indonesia menghabiskan sekitar tiga setengah jam per hari untuk mengakses media sosial. Dari laporan berjudul "Essential Insights Into Internet, Social Media, Mobile, and E-Commerce Use Around The World" yang diterbitkan tanggal 30 Januari 2018, dari total populasi Indonesia sejumlah 265,4 juta jiwa, pengguna aktif media sosialnya mencapai 130 juta dengan penetrasi 49 persen. Selain itu, lebih dari seratus juta orang Indonesia menggunakan perangkat mobile, seperti smartphone atau tablet untuk mengakses media sosial, dengan penetrasi 45 persen. Dalam sepekan, aktivitas online di media 
sosial melalui smartphone mencapai 37 persen. Berdasarkan aplikasi yang paling banyak diunduh, perusahaan media sosial di bawah Mark Zuckerberg mendominasi di tiga teratas. Secara berurutan dari posisi pertama adalah WhatsApp, Facebook, Instagram, dan baru diikuti media sosial buatan Korea Selatan, Line.(Kompas, 2018)

Oleh karena itu, aplikasi Whatsapp atau lebih dikenal dengan singkatan WA ini sangat cocok untuk diintegrasikan dalam sistem layanan perpustakaan yang murah dan mudah. Dengan pengintergrasian sistem layanan perpustakaan dengan WA, pemakai juga dapat dengan cepat mendapatkan informasi terkini tentang update informasi terbaru baik itu layanan ataupun koleksi yang ada di perpustakaan tanpa harus mengunjungi perpustakaan seca fisik namun cukup mengunjungi perpustakaan digitalnya. Pemustaka juga akan dapat dengan mudah memesan buku atau memperpanjang pinjaman mereka melalui aplikasi ini sehingga mereka juga akan dapat terhindar dari penalti (sanksi) dari keterlambatan pengembalian koleksi yang mereka pinjam.

\section{Kesimpulan}

Globalisasi menuntut pada perubahan yang cepat dan nyata karena hal ini juga berdampak pada tuntutan perpustakaan yang harus berubah susuai dengan perkembangan teknologi informasi. Walaupun dalam implementasinya penerapan teknologi informasi di perpustakaan perguruan tinggi masih mengalami kendala di berbagai sektor, namun mau tidak mau kita harus memiliki berbagai strategi agar mengatasi hal tersebut karen digitalisasi perpustakaan masih menjajikan banyak keuntungan-keuntungan terutama dalam kemudahan, kecepatan dan ketepatan dalam akses informasi oleh para pemustaka. Salah satu alternatif yang memang layak dikembangkan dalam memberikan kemudahan, kecepatan dan ketepatan layanan kepada para pemustaka adalah 
dengan mengembangkan layanan berbasis web yang dihubungkan dengan media sosial yang banyak digunakan oleh sivistas akademika saat ini, yaitu Watsapp.

Meskipun investasi untuk penerapan teknologi secara sempurna di perpustakaan memerlukan biaya yang tidak sedikit, namun kita yakin bahwa hasil yang akan diperoleh masih jauh lebih besar. Kita harus dapat meyakinkan semua pihak terutama stakeholder baik ditingkat institusi (rektor/ketua perguruan tinggi) maupun di tingkat kementerian (direktur DIKTIS/menteri) untuk memberikan perhatian khusus terhadap pengembangan perpustakaan perguruan berbasis teknologi agar standar layanannya minimal setara dengan perpustakaan perguruan tinggi di negara-negara maju.

Oleh karena itu semua pihak harus memiliki visi untuk perubahan demi kemajuan di masa depan karena kalau kita tidak berusaha untuk berubah maka jangan harap orang lain akan merubahnya sebahaimana firman Allah dalam Surat Ar-Ra'd ayat 11 ,yang artinya:

Sesungguhnya Allah tidak akan mengubah keadaan suatu kaum sebelum mereka mengubah keadaan mereka sendiri (QS. ArRa'd:11).

Ayat tersebut mengisyaratkan kepada kita akan pentingnya perubahan. Jika kita resis atau menetang perubahan kita pasti akan tertinggal karena perubahan adalah suatu keniscayaan. Memang pada umumnya perubahan tersebut dapat bersifat gradual dan dapat pula bersifat sistematis. Salah satu faktor penyebab perubahan yang paling nyata adalah globalisasi di mana kita hidup sekarang ini. Mudah-mudahan kita semua beserta perpustakaan perguruan tinggi kita dapat segera berubah ke arah 
yang lebih baik lagi sebagaimana yang dicita-citakan oleh bangsa ini.

\section{Daftar Pustaka}

Anwar, Ahmad. (2016). "Pemanfaatan Media Sosial dalam Pelayanan Referensi 2.0 di Indonesia". Jurnal Ilmu Perpustakaan, Informasi, dan Kearsipan Khizanah AlHikmah, Vol. 4, No. 1, 2016.

Departemen Agama RI. (1990). Alqur'an dan Tertjemahnya. Jakarta: Departemen Agama RI.

Ensiklopedo Nasional Indonesia. (2004). Jil. 16. Jakarta: Delta Pamungkas.

Grolier International Encyclopedia. (1998). Delux Home Edition, Connecticut: Grolier Incooperated.

Perpusnas RI. (2007). Undang-Undang No. 43 tentang Perpustakaan. Jakarta: Perpusnas RI.

Jacob E. Safira. (2003). The New Encyclopedia Britanica, 15th Ed., Vol. 28. Chicago: Encyclopedia Britanica Inc.

Johnson, Kay and Magusin, Elaine. Exploring the Digital Library: A Guide for Online Teaching and Learning. San Francisco: Jossey-Bass.

Kompas.com. "Riset Ungkap Pola Pemakaian Medsos Orang Indonesia", https:// tekno. kompas.com/read L2018/02/01/09270377/pengguna-aktif-bulanan. whatsapp, diakses pada: 04/10/2018)

Mukhlis. (2016). "Eksplorasi Model Pengembangan Perpustakaan Digital di Perpustakaan UIN Sunan Kalijaga Yogyakarta tahun 2014-2015". Jurnal Ilmiah LIBRIA, Vol.8, No.1 Juni 2016.

Hasanah, Nanan. (2010) "Implementasi Perpustakaan Digital di Institut Teknologi Bandung". Bogor : Jurnal Pustakawan Indonesia, Vol. 6, No. 1, 2010.

Pendit, Putu Laxman. (2008). Perpustakaan Digital dari $A-Z$. Jakarta: Cita Karyakarsa Mandiri.

Pendit, Putu Laxman. dkk. (2007). Perpustakaan Digital Perspektif Perpustakaan Perguruan Tinggi Indonesia. Jakarta: Sagung Seto.

Kristanti, Susana Rini. (editor). (2016). Mencari menemukan dan menggunakan informasi (seri literasi informasi). Jakarta: Graha Ilmu.

Kemendikbud. (2016). "Teknologi Informasi dan Komunikasi Penting untuk Proses Pembelajaran Masa Kini". http://www.kemdikbud.go.id. (Diakses pada: (13/11/2016). 
Subrata, Gatot. (2018). "Perpustakaan Digital". http://lib.mic.ac.id/perpus / Makalah/ KM\%20 Perpustakaan-2.pdf, (diakses pada:26/9/2018).

Surachman, Arief. (2018) 'Layanan Perpustakaan Berbasis Teknologi Informasi (TI)". https://sites. google. com/site/perpustakaanfti/artikel-perpustakaan-digital/ layanan-perpustakaan-berbasis-teknologi-informasi-ti, (diakses pada: 26/09/2018)

Tim Penyusun Kamus Pusat Pembinaan dan Pengembangan Bahasa Departemen Pendidikan dan Kebudayaan. (1999). Kamus Besar Bahasa Indonesia, Edisi Kedua. Jakarta: Balai Pustaka.

Wahyuni, Deby Sry. (2018). "Membangun Perpustakaan Berbasis Teknologi", https://sites. google .com/ site/ perpustakaanfti/artikel-perpustakaan-digital/ paradigmakonsep-dan-teknologi-informasi-yang-digunakan/ membangun-perpustakaan- berbasis-teknologi (diakses pada: 26/09/2018).

Wikipedia Bahasa Indonesia. "Teknologi Informasi", ensiklopedia bebas. https:// id.wikipedia.org/wiki/Teknologi_informasi, (diakses pada: 25/09/2018). 